This is the peer reviewed version of the following article:

Briggs, A. and Sun, W. and Miller, L. and Geelhoed, E. and Huska, A. and Inderjeeth, C. 2015. Hospitalisations, admission costs and re-fracture risk related to osteoporosis in Western Australia are substantial: A 10-year review. Australian and New Zealand Journal of Public Health. 39 (6): pp. 557-562.,

which has been published in final form at http://doi.org/10.1111/1753-6405.12381

This article may be used for non-commercial purposes in accordance with Wiley Terms and Conditions for Self-Archiving at http://olabout.wiley.com/WileyCDA/Section/id820227.html\#terms 


\section{Hospitalisations, admission costs and re-fracture risk related to osteoporosis in Western Australia are substantial: a 10-year review.}

Andrew M. Briggs ${ }^{1,2, *}$ (A.Briggs@curtin.edu.au)

Wenxing Sun ${ }^{3}$ (Wenxing.Sun@health.wa.gov.au)

Laura J. Miller ${ }^{3}$ (Laura.Miller@health.wa.gov.au)

Elizabeth Geelhoed ${ }^{4}$ (Elizabeth.Geelhoed@uwa.edu.au)

Anna Huska ${ }^{3}$ (Anna.Huska@health.wa.gov.au)

Charles A. Inderjeeth ${ }^{5,6}$ (Charles.Inderjeeth@health.wa.gov.au)

${ }^{1}$ School of Physiotherapy \& Exercise Science, Curtin University, Perth, WA.

${ }^{2}$ Arthritis and Osteoporosis Victoria, Melbourne, VIC.

${ }^{3}$ Department of Health, Government of Western Australia, Perth, WA.

${ }^{4}$ School of Population Health, University of Western Australia, Perth, WA.

${ }^{5}$ Rehabilitation and Aged Care, North Metropolitan Health Service, Perth, WA.

${ }^{6}$ School of Medicine and Pharmacology, University of Western Australia, Perth, WA.

* Corresponding author

Associate Professor Andrew M Briggs

School of Physiotherapy and Exercise Science, Curtin University

GPO Box U1987, PERTH, WA 6845

$\mathrm{T}:+61892664644$

F: +61892663699

E: A.Briggs@curtin.edu.au 


\section{Acknowledgements}

The authors gratefully acknowledge the assistance of the Data Linkage Branch (Alexandra Godfrey, Mikhalina Dombrovskaya) and the Performance, Activity and Quality Division (William Pyper), Department of Health (WA) in providing linked data for this study. 


\section{Hospitalisations, admission costs and re-fracture risk related to osteoporosis in Western Australia are substantial: a 10-year review.}

Abstract

Objective: To quantify hospitalisation costs to Western Australia (WA) for osteoporosis-related fractures, and estimate risk of re-admission after incident fracture.

Methods: All hospitalisation records for WA residents aged $\geq 50$ years admitted to a WA hospital between 2002-2011 due to osteoporotic fractures were extracted from the WA Hospital Morbidity Data System. Data linkage enabled identification of the first (index) fracture admission, determination of subsequent osteoporotic fracture-related readmissions, and quantification of total admission costs and bed days. Cox proportional hazard models assessed factors influencing first readmission.

Results: 5,326 patients were admitted to WA hospitals for an index fracture. Of the 2,037 (38.2\%) patients who sustained a re-fracture requiring readmission, 1,223 (23.0\%) sustained one re-fracture episode, 453 (8.5\%) sustained two, and 361 (6.8\%) sustained $\geq 3$ re-fracture episodes requiring readmission. Cost of index admissions was $\$ A \cup 57,007,262$ while $\$ A \cup 48,948,623$ was associated with readmissions (CPI-adjusted to 2011/12). Cumulative probability of readmission within 6 months of the index admission was $20 \%$ (males) and $17 \%$ (females).

Conclusions: Osteoporotic fracture-related hospitalisations impose a substantial financial impact to WA, exceeding $\$ A \cup 100 M$ in a decade.

Implications: Considering the large system costs, policy and programmes to improve identification of index fractures and initiation of osteoporosis treatments and primary prevention initiatives are justified

Keywords: osteoporosis, fracture, admission, re-admission, data linkage, cost, risk 


\section{Introduction}

Osteoporosis is a skeletal condition characterised by a decrease in bone mass and quality which reduces bone strength and increases propensity to fracture. The impact of osteoporotic fractures on people is substantial. They are associated with significant physical and psychological impacts ${ }^{1}$. Mortality and morbidity associated with osteoporotic fractures, expressed as disability-adjusted life years (DALYs), exceed those for many other chronic health conditions ${ }^{2}$, representing a substantial personal and socioeconomic burden at a state level ${ }^{3}$, national level ${ }^{4}$, and globally ${ }^{5}$.

Although data from the last decade indicate the age-specific rate of fractures is declining in Western populations, including Australia, the absolute number of people who sustain fractures will increase in coming years as the population ages ${ }^{4,6}$, increasing the burden of disease attributed to osteoporosis. Importantly, once an initial fracture is sustained (an incident fracture), the risk of refracture rises markedly, particularly in the first year ${ }^{7}$ and exponentially for every subsequent fracture sustained thereafter ${ }^{8,9}$. Therefore, the 'time to next fracture' represents an important window for preventive intervention to minimise a fracture cascade and improve health outcomes. In 2001, a hospitalisation for a fracture related to osteoporosis occurred every 8.1 minutes in Australia, increasing to every 5-6 minutes in 2007 and every 3.6 minutes in 2013. By 2022, the rate will increase to one fracture every 2.9 minutes ${ }^{4}$. More Australians sustaining more fractures, taken in parallel with increasing morbidity impacts and mortality risks associated with each fracture sustained, will undoubtedly place enormous pressure on our health systems, particularly emergency, radiology and orthopaedic surgery departments, and residential aged care facilities. It is critical, therefore, that effective, systemic reforms are initiated to deal with these projections ${ }^{10,11}$.

At state jurisdictional levels, both Western Australia (WA) and New South Wales (NSW) have developed, through their Musculoskeletal Networks, evidence-informed Models of Care to deal with the impact of osteoporosis at a system-wide level ${ }^{3,10,12}$, particularly the re-fracture cascade. The principal recommendation from these Models of Care is to establish fracture liaison services (FLSs) 
within health systems, consistent with recent international position statements ${ }^{13-15}$. The role of FLSs is to coordinate the timely identification, assessment and appropriate multidisciplinary management of people who sustain incident osteoporotic fractures as a means to reduce the risk of recurrent fracture. Recent data from Australia and internationally substantiate the clinical efficacy and costeffectiveness of these services ${ }^{16-18}$. However, examining local system costs prior to the introduction of such system-wide reforms is necessary to determine local cost effectiveness of such initiatives and to provide relevant data to policy makers, including baseline metrics.

While the system impact of re-fractures has been modelled in NSW using data from three hospital sites $^{19}$, no such data exist for WA. The NSW data identified an increase in the number of patients admitted for treatment of fractures over the last 5 years and that introduction of a FLS-based Model of Care would reduce the number of patients re-admitted for an osteoporotic fracture by $10 \%$. While informative, the NSW modelling did not use linked data across all hospital sites, representing a methodological limitation. WA has a history of excellence in data linkage systems, providing the opportunity to accurately identify all admissions across the state ${ }^{20}$. The total population prevalence of osteoporosis in WA is comparable to that of other states, based on the 2011-12 Australian Health Survey ${ }^{21}$.

Quantifying the cost burden associated with health conditions is complex and often requires multiple methodological assumptions, particularly related to indirect costs, which may lead to variable findings. For this reason, quantification of direct hospital costs may be preferable to derive an accurate, albeit non-exhaustive, cost burden ${ }^{22}$. These data are important to inform decision making regarding planning, resourcing and evaluating health service activity, particularly in the context of osteoporosis ${ }^{22}$. As a means to quantify the impact of osteoporotic re-fractures at a system-level, the aim of this study was to undertake an analysis of the occurrence of re-fractures due to osteoporosis requiring hospitalisation in WA over a decade. In particular, this study aimed to: i) describe the number of hospitalisations, re-admissions, bed days and treatment costs incurred; ii) 
determine the time to first re-admission for osteoporotic fracture; and ii) estimate the risk of refracture due to osteoporosis over 10 years.

\section{Methods}

\section{Study design and data extraction}

All hospitalisations due to osteoporotic fracture in people aged $\geq 50$ years resident in WA between 1 January 2002 and 31 December 2011 were identified from the WA Hospital Morbidity Data System (HMDS, http://www.health.wa.gov.au/healthdata/resources/hmds.cfm). An age threshold of $\geq 50$ years was selected since minimal-trauma fractures are uncommon in people aged less than 50 years and to enable comparability with similar analyses conducted in NSW ${ }^{19}$ and consistency with recent Australian ${ }^{4,23,24}$ and international ${ }^{22}$ osteoporosis studies. A window of 10 years was selected since mortality and re-fracture risk is greatest in the first 5 years following an incident fracture, with risk profiles plateauing at 10 years ${ }^{9}$.

After extraction of all people $\geq 50$ years with a hospitalisation due to osteoporotic fracture between 2002 and 2011, all linked hospital separation records for the same patient within the HMDS were added. This linkage process enabled the identification of the first (index) admission for osteoporotic fracture for that individual among multiple admissions within the study period, the determination of subsequent osteoporotic fracture-related readmissions to any hospital in WA (public or private) within the study period, and each patient's total cost and length of stay by combining hospital records associated with the same diagnostic episode.

The first (index) admission was defined as individuals who had a hospital record involving an ICD-10AM diagnostic code of M80.x (osteoporosis with pathological fracture and ' $x$ ' represents any value between 0-9) in any diagnosis field in 2002-2011. Therefore, index cases reflect the first hospital 
admission for an osteoporotic-fracture within the study period, and not necessarily the first ever admission for an osteoporotic fracture sustained by an individual. Re-admission episodes were defined by 1) hospital separations involving an ICD-10-AM diagnostic code of M80.x recorded in any diagnosis field on the inpatient discharge summary; or 2) hospital separations involving one of the ICD-10-AM fracture S or T diagnostic codes and a W "minimal trauma" fracture injury mechanism code (Supplementary Material 1). Recognising that a proportion minimal-trauma fractures due to osteoporosis are not coded explicitly by hospitals as an "osteoporotic fracture" (M80) ${ }^{25,26}$, identification of re-fracture episodes requiring admission in individuals who sustained index osteoporotic fractures (defined by ICD-10-AM as M80) requiring admission was undertaken with broader criteria. Indeed, using broader criteria in this context is recommended ${ }^{27}$ and our criteria were consistent with the method used in NSW ${ }^{19}$.

Patient characteristics (age at admission, gender) and hospitalisation details (other diagnoses, Diagnostic Related Groups (DRG), admission and separation dates) were extracted, consistent with methods reported previously ${ }^{28}$. Date of death data obtained from the WA Mortality Registry were used in the statistical analysis and linked to patients in the hospital data through the Data Linkage System.

\section{Data analysis}

Hospital separations associated with the same osteoporotic/low trauma fracture episode of care (including hospital transfers) were combined to avoid over-counting the number of re-admissions. Costs and hospital bed days of transfer records were summed for the same episode. The costs were derived using National Public Cost Weight Tables which are based on DRGs. They were then adjusted for the Consumer Price Index (CPI) relative to 2011/12 financial year prices.

Cox proportional hazard models were used to assess factors influencing time to first re-admission for osteoporotic fracture including age, gender, bed days of the index episode and DRG-coded co- 
morbidities or therapies known to influence fracture risk; including diabetes, asthma, rheumatoid arthritis, thyroid and parathyroid disorders, malabsorption-related conditions, autoimmune diseases, chronic kidney and liver diseases, chemotherapy, adverse effects of glucocorticoids and androgen deprivation therapy. These predictor variables were selected a priori based on data available to us in the HMDS and clinically-meaningful factors. The co-morbidities and therapies were identified based on our clinical judgement and the available DRG codes. The time-to-event variable was the days from the index separation date to the first re-admission date for patients who had a readmission, or date of death for patients with no re-admission who died before the end of the study. Patients with no re-admission or death during the study period were censored at 31 December 2011. For Cox regression models only, a look-back period of 10 years prior to 1 January 2002 was undertaken to identify and remove patients who were admitted for an osteoporotic fracture (M80.x or equivalent ICD-9 code, 733.1x any diagnosis field) before 2002 to increase certainty that patients sustained their first (index) fracture during 2002-2011. While this approach does not provide absolute certainty that index admissions within the study period reflected first ever admissions for osteoporotic fractures sustained by individuals within the study period, it provides a level of increased assurance for the purposes of examining associations between index events and a prioridefined factors. The look-back was not applied to cost estimates as we sought to calculate the true system cost to WA over the decade, and thus, did not exclude cases for these estimates.

Kaplan-Meier curves were used to test whether the hazard for male and female remained proportional across the duration. A cross-over at approximately 2 years (782 days) suggested gender violated proportional hazard assumption. Consequently, the risk of re-admission between genders was compared in separate models, before and after the cross over point and for the whole study period. The interactions between risk factors and the log time-to-first re-admission were included in models to test proportional hazard assumptions for risk factors. When the assumptions were 
violated, the interaction terms were adjusted in the final model. All analyses were carried out in SAS enterprise guide 5.1 .

\section{Ethics and data access statement}

The study was approved by the Human Research Ethics Committee of the WA Department of Health and the WA Data Linkage Unit.

\section{Results}

Index and recurrent fractures and associated costs

During the study period (2002 - 2011), 5,326 patients were admitted (index admissions) to WA hospitals due to an osteoporosis-related fracture; 1,155 were males (21.7\%) and 4,171 were females (78.3\%). 379 males (32.8\%) and 1,658 females (39.8\%) sustained at least one re-fracture episode, respectively, within the decade period (Table 1).

Of the 2,037 (38.2\%) patients who sustained a re-fracture requiring hospitalisation, 1,223 (23.0\%) patients sustained one re-fracture episode, 453 (8.5\%) sustained two re-fracture episodes, and 361 (6.8\%) sustained three or more re-fracture episodes requiring readmission within the decade period.

A total of 3,646 re-admissions were observed during the 10 years (a mean of 1.8 readmissions per patient). The number of patients admitted for an index event decreased over the study period, while the number of re-admissions increased between 2002 and 2004 and then plateaued due to the limited observation period for patients who had an index fracture in later years of the decade studied (Table 1) .

A total of 75,182 bed days related to 3,646 re-admissions (average 20.6 bed days per re-admission) was recorded. Despite the number of re-admissions plateauing after 2004, the bed days continued 
to increase. The average bed days per re-admission increased linearly over time. Table 1 provides summary statistics on re-admissions by year across the study period.

The total CPI-adjusted cost of the index hospitalisations due to osteoporotic fractures was $\$ 57,007,262$ in the 10 years period (mean cost per patient $\$ 10,704)$. An additional $\$ 48,948,623$ was associated with readmissions after the index hospitalisation (mean cost per patient $\$ 24,030$ ) within the decade period. The total, mean and median costs per re-admission increased linearly over the decade after adjusting for the CPI (Table 1).

Time between incident fracture and re-admissions

Of the 2,037 patients who were re-admitted for a re-fracture within the decade period, $44.4 \%$ were readmitted within less than 6 months, $13.1 \%$ within 6 months to $<1$ year, $17.4 \%$ within 1 to $<2$ years, $10.5 \%$ within 2 to $<3$ years, and $14.6 \%$ within 3 or more years of the index admission. Male patients had a higher proportion of re-admissions (56.7\%) within the first 6 months than female patients (41.6\%).

Risk of admission for re-fracture

Of the 5,326 patients with hospital separations for osteoporotic fracture between 2002 and 2011, 503 were removed from the Cox regression analysis as they had a separation for osteoporotic fracture before 2002. The Kaplan-Meier survival curve (Figure 1) illustrates the changing relationship between the likelihood of re-admission for re-fracture in males and females over time. Although a greater cumulative proportion of males were admitted in the first 2 years, this trend reversed after 2 years with a greater proportion of females readmitted. However, these trends observed before and after two-year cross-over point were not significant after adjusting for age, co-morbidities and bed days (using male as the reference $\mathrm{HR}=0.83,95 \% \mathrm{Cl}=0.61-1.13 ; \mathrm{p}=0.233$ and $\mathrm{HR}=1.27,95 \% \mathrm{Cl}=$ 1.00-1.69; $p=0.098$ ). 
The descriptive data summarised in Table 2 demonstrates female patients in the study were older than male patients. In both sexes, age was similar between patients with and without re-admissions. The proportions of comorbidities among patients with and without re-admissions were also similar.

The risk of first re-admission for re-fracture among males increased by $3 \%$ and $5 \%$ for every one year increase in age and every additional bed day during the index admission, respectively. In males with asthma or adverse effects from glucocorticoids or androgen deprivation therapy, the risk of readmssion was approximately 2 or 3 times greater, respectively (Table 2). The risk of first readmission for females increased by $3 \%$ for every additional bed day during the index admission. Age had no significant influence on the risk of first re-admission in females. Chronic liver disease was associated with an $51 \%$ increase in the risk of first re-admission for female patients (Table 2).

\section{Discussion}

Using linked-data, we have identified a substantial direct hospital cost to WA for low-trauma fractures related to osteoporosis, exceeding \$AUD100 million over a ten year period. While this magnitude of cost is alarming, of greater concern is the observation that direct hospital costs per readmission for fracture increased in parallel with length of stay over the period. These data highlight the need for system reform initiatives to stem the flow of recurrent fractures among people with osteoporosis ${ }^{11}$. Our data suggest that $38 \%$ of patients with an index event are re-admitted for fracture(s) within a 10 year period and more than $50 \%$ of these re-admissions occur within the first year, highlighting this window as a critical period for preventive interventions.

Over the ten year period, we observed a linear decline in the incidence of index admissions. These trends, however, should be interpreted within the context of the definitions for index admissions and re-admissions used in this study. That is, index admissions refer to first admissions within the study period, not first ever admissions. It is likely, therefore, that many of the admission events 
identified in the earlier years of the study period actually reflect re-admissions for osteoporotic fractures, thereby overestimating first fracture (index) admissions and under-estimating readmissions for fracture. Irrespective of this, the total costs measured are still accurate as they are based on DRG-defined episodes of care for which standard costs exist. The observed decline in index admissions in the later years of the study is more likely to represent a decline in true index events. This observation is consistent with other international and Australian data pointing to a decline in incident fracture rates, potentially attributable to improved diagnosis and treatment practices for falls and bone health, particularly the introduction of PBS-subsidised bisphosphonate medications in the early $2000^{\prime} s^{29,30}$. We observed an increase in re-admissions for fractures between 2002-2006, with a plateau and slight decline thereafter. The plateau and decline in re-admissions may also reflect improved management practices for osteoporotic fractures; particularly the introduction of bisphosphonate therapies for osteoporosis in the early 2000's where PBS-subsidised therapies were made available for secondary fracture prevention, and possibly education interventions in WA through professional bodies and arthritis and osteoporosis advocacy organisations ${ }^{31}$. This may advocate for the consideration of the role of multimodal fracture liaison programs to better identify, investigate and treat as important secondary prevention strategies.

The average cost per re-admission (CPI-adjusted for 2011/12 prices) rose linearly over the decade which is directly related to a progressively increasing length of stay for re-admissions. While we cannot infer causation for this observation, we speculate it may be due to cohort ageing and a potentially increasing co-morbidity burden over the decade. These data suggest it is critical, therefore, to initiate preventive interventions after incident fracture, particularly in elderly patients, given the trajectory of increasing costs for the state health system and benefits to the health of the individuals.

In both males and females, increasing length of stay during the index admission increased the risk of re-admission for re-fracture, suggesting that timely clinical attention to the index fracture event and 
other diagnoses associated with the index admission are important to improve outcomes. For example, time to surgical intervention for hip fracture exceeding 48 hours is associated with poorer outcomes ${ }^{32}$. Increased length of stay during an index admission may partly reflect the increased frailty and/or comorbidities in this cohort requiring pre-surgical optimisation and higher comorbid complications during their admission. In females, risk of re-admission was not influenced by age, suggesting that interventions in any female aged $\geq 50$ years with osteoporotic fracture is important, particularly those with chronic liver disease. For males, increasing age was associated with readmission risk, highlighting the importance of clinical attention in elderly males with osteoporotic fracture. Similarly, increased vigilance is warranted in males with asthma or being treated with glucocorticoid or androgen deprivation therapies given that fracture risk associated with these agents is high and not necessarily commensurate with bone mineral density ${ }^{33,34}$.

With an ageing population and potentially longer length of stay and escalating costs to manage fractures in an older, frailer demographic, more negative outcomes are likely when intervention strategies are delayed. Some strategies already in place go some way to address this such as falls prevention programs, subsidised access to screening and primary prevention pharmacotherapies. However, these strategies have limited reach and efficacy and preventable fracture rates remain high, contributing to the enormous burden of disease imposed by osteoporosis. For example, falls were the leading cause of injury requiring hospitalisation in Australians aged 65 years and older in 2011-12 and fractures were the most common type of injury associated with a fall ${ }^{35} .$. In this study we observed that the majority of re-admissions occurred within the first year after the incident fracture, consistent with previously reported data ${ }^{8}$ and likely reflects the immediate and substantial health impact of osteoporotic fractures. Timely identification of people sustaining incident fractures is therefore critical in the first year to avert downstream consequences of re-fracture. Internationally, efforts are underway to implement systems to arrest the fragility fracture cycle, 
principally through the implementation of fracture liaison services. For example, the International Osteoporosis Foundation recently launched a report summarising contemporary international data on incident fracture rates, associated costs and re-fracture risks ${ }^{15}$.

A substantial strength of this study is the use of state-wide linked data. This approach ensured we accurately captured all index and re-admissions across all hospitals in WA within the ten year window of interest and represents a methodological advance over previous work ${ }^{19}$. The results reported here should be interpreted in the context of some methodological limitations. First, our case ascertainment was limited to people who were admitted to WA hospitals, and thus did not consider resource implications for fractures that did not come to clinical attention or those managed in primary care or in emergency departments. Second, our costs estimates were based on direct DRG-derived costs attributed to the hospital stay and therefore did not consider indirect costs, which are known to be substantial ${ }^{4}$. For example, in a recent modelling report, indirect costs of musculoskeletal diseases accounted for the majority (83\%) of total costs to the Australian community in $2012^{21}$. Further, these DRG-derived costs related to the primary diagnosis field on the medical record. In circumstances where the primary diagnosis was not an osteoporotic fracture, the DRG-derived cost may over or under-estimate the cost attributed to the management of the osteoporotic fracture. This limitation is balanced somewhat by the fact that not all osteoporotic fractures coming to clinical attention are coded as such and therefore, we may underestimate the total system impact of these episodes of care. Future work could utilise the alternative methods for estimating unit costs that have been proposed more recently ${ }^{4}$, and could examine the relationships between fracture types and system outcomes. Finally, our definition for index admission referred to the first admission for an osteoporotic fracture within the study period. As such, index admissions don't necessarily reflect a true first admission for fracture, and therefore our observations in the initial years of the study period may underestimate the true rate of re-admissions and thus true readmission cost in the earlier years. 


\section{Conclusion}

Osteoporotic fracture-related hospitalisations impose a substantial financial impact to WA, exceeding \$AU100M in a decade. The risk of hospitalisation for re-fracture rises markedly after an index fracture, particularly within the first 12 months and particularly in high risk groups. These data provide further justification for the implementation of Fracture Liaison Services in health services.

Figure legend

Figure 1 Kaplan-Meier survival curve for cumulative probability of first re-admission by gender.

\section{Acknowledgements}

(included with blinded title page)

\section{References}

1. Papaioannou A, Kennedy CC, loannidis G, et al. The impact of incident fractures on healthrelated quality of life: 5 years of data from the Canadian Multicentre Osteoporosis Study. Osteoporos Int 2009;20:703-14.

2. Johnell $\mathrm{O}$, Kanis JA. An estimate of the worldwide prevalence and disability associated with osteoporotic fractures. Osteoporos Int 2006;17:1726-33.

3. Department of Health Western Australia. Osteoporosis Model of Care. Perth: Health Networks Branch; 2011. 
4. Watts JJ, Abimanyi-Ochom J, Sanders KM. Osteoporosis costing all Australians. A new burden of disease analysis 2012-2022. Sydney: Osteoporosis Australia; 2013.

5. Mithal A, Ebeling P, Kyer CS. The Asia-Pacific Regional Audit. Epidemiology, costs \& burden of osteoporosis in 2013. Nyon: International Osteoporosis Foundation; 2013.

6. Pasco JA, Brennan SL, Henry MJ, et al. Changes in hip fracture rates in southeastern Australia spanning the period 1994-2007. J Bone Miner Res 2011;26:1648-54.

7. Lindsay R, Silverman SL, Cooper C, et al. Risk of new vertebral fracture in the year following a fracture. JAMA 2001;285:320-3.

8. Center JR, Bliue D, Nguyen TV, Eisman JA. Risk of subsequent fracture after low-trauma fracture in men and women. JAMA 2007;297:387-94.

9. Bliuc D, Nguyen TV, Eisman JA, Center JR. The impact of non-hip non-vertebral fractures in elderly women and men. J Clin Endocrinol Metab 2014;99:415-23.

10. Briggs AM, Towler SC, Speerin R, March LM. Models of care for musculoskeletal health in Australia: now more than ever to drive evidence into health policy and practice. Aust Health Rev 2014;38:401-5.

11. Speerin R, Slater $\mathrm{H}$, Li LC, et al. Moving from evidence to practice: Models of care for the prevention and management of musculoskeletal conditions. Best Pract Res Clin Rheumatol 2014;http://dx.doi.org/10.1016/j.berh.2014.07.001.

12. NSW Agency for Clinical Innovation. Musculoskeletal Network: NSW Model of Care for Osteoporotic Refracture Prevention. Sydney: NSW Agency for Clinical Innovation; 2011.

13. Eisman JA, Bogoch ER, Dell R, et al. Making the first fracture the last fracture: ASBMR task force report on secondary fracture prevention. J Bone Miner Res 2012;27:2039-46.

14. Akesson K, Marsh D, Mitchell PJ, et al. Capture the Fracture: a Best Practice Framework and global campaign to break the fragility fracture cycle. Osteoporos Int 2013;24:2135-52.

15. Akesson K, Mitchell P. Capture the fracture. A global campaign to break the fragility fracture cycle. Nyon: International Osteoporosis Foundation; 2012. 
16. Cooper MS, Palmer AJ, Seibel MJ. Cost-effectiveness of the Concord Minimal Trauma Fracture Liaison service, a prospective, controlled fracture prevention study. Osteoporos Int 2012;23:97-107.

17. Lih A, Nandapalan $\mathrm{H}$, Kim M, et al. Targeted intervention reduces refracture rates in patients with incident non-vertebral osteoporotic fractures: a 4-year prospective controlled study. Osteoporos Int 2011;22:849-58.

18. Marsh D, Akesson K, Beaton DE, et al. Coordinator-based systems for secondary prevention in fragility fracture patients. Osteoporo Int 2011;22:2051-65.

19. Aspex Consulting. Formative evaluation of the osteoporotic re-fracture prevention project. Final evaluation report. Sydney: NSW Health Agency for Clinical Innovation; 2012.

20. Holman CD, Bass AJ, Rosman DL, et al. A decade of data linkage in Western Australia: strategic design, applications and benefits of the WA data linkage system. Aust Health Rev 2008;32:766-77.

21. Arthritis and Osteoporosis Victoria. A problem worth solving. The rising cost of musculoskeletal conditions in Australia. Melbourne: Arthritis and Osteoporosis Victoria 2013.

22. Hopkins RB, Tarride JE, Leslie WD, et al. Estimating the excess costs for patients with incident fractures, prevalent fractures, and nonfracture osteoporosis. Osteoporos Int 2013;24:58193.

23. Brennan SL, Henry MJ, Kotowicz MA, Nicholson GC, Zhang Y, Pasco JA. Incident hip fracture and social disadvantage in an Australian population aged 50 years or greater. Bone 2011;48:607-10.

24. Sanders KM, Nicholson GC, Watts JJ, et al. Half the burden of fragility fractures in the community occur in women without osteoporosis. When is fracture prevention costeffective? Bone 2006;38:694-700. 
25. Lix LM, Azimaee M, Osman BA, et al. Osteoporosis-related fracture case definitions for population-based administrative data. BMC Public Health 2012;12.

26. Narongroeknawin P, Patkar NM, Shakoory B, et al. Validation of diagnostic codes for subtrochanteric, diaphyseal, and atypical femoral fractures using administrative claims data. J Clin Densitom 2012;15:92-102.

27. Lix LM, Yogendran MS, Leslie WD, et al. Using multiple data features improved the validity of osteoporosis case ascertainment from administrative databases. J Clin Epidemiol $2008 ; 61: 1250-60$.

28. Somerford PJ, Lee AH, Yau KK. Ischemic stroke hospital stay and discharge destination. Ann Epidemiol 2004;14:773-7.

30. Abrahamsen B, Vestergaard P. Declining incidence of hip fractures and the extent of use of anti-osteoporotic therapy in Denmark 1997-2006. Osteoporos Int 2010;21:373-80.

31. Fisher AA, O'Brien ED, Davis MW. Trends in hip fracture epidemiology in Australia: Possible impact of bisphosphonates and hormone replacement therapy. Bone 2009;45:246-53.

32. Inderjeeth CA, Glennon DA, Poland KE, et al. A multimodal intervention to improve fragility fracture management in patients presenting to emergency departments. Med J Aust 2010;193:149-53.

33. Mak JCS, Cameron ID, March LM. Evidence-based guidelines for the management of hip fractures in older persons: an update. Med J Aust 2010;192:37-41.

34. Van Staa TP, Laan RF, Barton IP, Cohen S, Reid DA, Cooper C. Bone density threshold and other predictors of vertebral fracture in patients receiving oral glucocorticoid therapy. Arthritis Rheum 2003;48:3224-9.

35. Manning LI, Briggs AM, Van Doornum S, Kale A, Kantor S, Wark JD. Glucocorticoid-induced bone loss is associated with abnormal intravertebral areal bone mineral density distribution. Int J Endocrinol 2013;2013:768579. 
36. Tovell A, Harrison JE, Pointer S. Hospitalised injury in older Australians, 2011-12. Injury research and statistics series no. 90. Canberra: AlHW; 2014. 


\section{Tables}

Table 1 Summary statistics of re-admissions, associated length of stay and DRG-derived costs across the decade, presented by year of re-admission.

\begin{tabular}{|c|c|c|c|c|c|c|c|c|c|c|c|}
\hline \multirow[t]{2}{*}{$\begin{array}{l}\text { Year of } \\
\text { re-admission }\end{array}$} & \multicolumn{3}{|c|}{ Number of patients } & \multicolumn{4}{|c|}{ Bed days } & \multicolumn{4}{|c|}{$\begin{array}{l}\text { CPI-adjusted^ DRG-derived costs for re-admissions } \\
\text { (\$AUD) }\end{array}$} \\
\hline & $\begin{array}{c}\text { Admitted for } \\
\text { index } \\
\text { fracture }^{\#}\end{array}$ & $\begin{array}{l}\text { Re-admitted } \\
\text { for fracture } \\
(\%)\end{array}$ & $\begin{array}{c}\mathrm{N} \text { re- } \\
\text { admissions }\end{array}$ & Total & $\begin{array}{l}\text { Average } \\
\text { per } \\
\text { patient }\end{array}$ & $\begin{array}{l}\text { Median (LQ } \\
\text { - UQ)‡ per } \\
\text { patient }\end{array}$ & $\begin{array}{l}\text { Average } \\
\text { per re- } \\
\text { admission }\end{array}$ & Total & $\begin{array}{c}\text { Average } \\
\text { per } \\
\text { patient }\end{array}$ & $\begin{array}{c}\text { Median (LQ - } \\
\text { UQ)‡ per } \\
\text { patient }\end{array}$ & $\begin{array}{c}\text { Average } \\
\text { cost per } \\
\text { re- } \\
\text { admission }\end{array}$ \\
\hline 2002 & 734 & $71(9.7)$ & 189 & 1,929 & 27 & $16(8-33)$ & 10.21 & $1,089,869$ & 15,350 & $\begin{array}{c}8,201 \\
(5,348-22,202)\end{array}$ & 5,767 \\
\hline 2003 & 674 & $128(19.0)$ & 302 & 4,393 & 34 & $21(8-40)$ & 14.55 & $2,574,391$ & 20,112 & $\begin{array}{c}13,532 \\
(7,117-27,794)\end{array}$ & 8,524 \\
\hline 2004 & 683 & $166(24.3)$ & 410 & 5,231 & 32 & $18(10-46)$ & 12.76 & $3,093,754$ & 18,637 & $\begin{array}{c}14,514 \\
(8,306-23,301)\end{array}$ & 7,546 \\
\hline 2005 & 524 & 199 (38.0) & 427 & 7,574 & 38 & $25(10-49)$ & 17.74 & $4,583,472$ & 23,033 & $\begin{array}{c}16,805 \\
(8,657-33,381)\end{array}$ & 10,734 \\
\hline 2006 & 612 & $225(36.8)$ & 436 & 8,397 & 37 & $27(11-45)$ & 19.26 & $5,389,714$ & 23,954 & $\begin{array}{c}17,831 \\
(9,156-31,756)\end{array}$ & 12,362 \\
\hline 2007 & 515 & $243(47.2)$ & 424 & 8,579 & 35 & $23(10-50)$ & 20.23 & $5,722,600$ & 23,550 & $\begin{array}{c}18,423 \\
(9,526-34,052)\end{array}$ & 13,497 \\
\hline 2008 & 428 & 225 (52.6) & 363 & 9,325 & 41 & $29(14-56)$ & 25.69 & $5,891,661$ & 26,185 & $\begin{array}{c}21,217 \\
(10,369-34,677)\end{array}$ & 16,230 \\
\hline 2009 & 380 & 244 (64.2) & 376 & 10,395 & 43 & $28(12-59)$ & 27.65 & $6,448,739$ & 26,429 & $\begin{array}{c}19,631 \\
(8,087-38,078)\end{array}$ & 17,151 \\
\hline 2010 & 400 & 230 (57.5) & 342 & 8,361 & 36 & $26(10-51)$ & 24.45 & $6,178,519$ & 26,863 & $\begin{array}{c}20,105 \\
(9,771-40,366)\end{array}$ & 18,066 \\
\hline 2011 & 376 & 306 (81.4) & 377 & 10,998 & 36 & $25(10-47)$ & 29.17 & $7,975,904$ & 26,065 & $\begin{array}{c}20,036 \\
(10,201-37,025)\end{array}$ & 21,156 \\
\hline Total & 5,326 & 2,037 (38.2) & 3,646 & 75,182 & 37 & $25(10-50)$ & 20.62 & $48,948,623$ & 24,030 & $\begin{array}{c}18,409 \\
(8,865-34,072)\end{array}$ & 13,425 \\
\hline
\end{tabular}


${ }^{\wedge}$ costs adjusted to 2011/12 consumer price index (CPI) to reflect costs in 2011/12

\# index fracture admission refers to the first fracture requiring within the study period

‡ LQ: lower quartile; UQ: upper quartile 
Table 2

Patient demographics, descriptive statistics and hazard ratios for factors associated with first re-admission from Cox regression, 2002-2011.

\begin{tabular}{|c|c|c|c|c|c|c|c|c|}
\hline \multirow[b]{2}{*}{ Risk factor } & \multicolumn{4}{|c|}{ Males } & \multicolumn{4}{|c|}{ Females } \\
\hline & $\begin{array}{c}\text { Had re- } \\
\text { admission } \\
(n=333)\end{array}$ & $\begin{array}{c}\text { No re- } \\
\text { admission } \\
(n=663)\end{array}$ & $\begin{array}{l}\text { Hazard } \\
\text { Ratio\# }\end{array}$ & $95 \% \mathrm{Cl}$ & $\begin{array}{c}\text { Had re- } \\
\text { admission } \\
(n=1437)\end{array}$ & $\begin{array}{c}\text { No re- } \\
\text { admission } \\
(n=2203)\end{array}$ & $\begin{array}{l}\text { Hazard } \\
\text { Ratio } \ddagger\end{array}$ & $95 \% \mathrm{Cl}$ \\
\hline Demographic & mean & mean & & & mean & mean & & \\
\hline Age at index admission & 78.41 & 78.54 & 1.03 & $1.01-1.05 *$ & 81.54 & 80.64 & 1.00 & $1.00-1.01$ \\
\hline Bed days at index admission & 16.35 & 22.45 & 1.05 & $1.00-1.10 *$ & 19.10 & 20.36 & 1.03 & $1.01-1.05^{*}$ \\
\hline Co-morbidities ${ }^{\wedge}$ & n (\%) & n (\%) & & & n (\%) & n (\%) & & \\
\hline Rheumatoid arthritis & $15(4.50)$ & $23(3.47)$ & 1.26 & $0.75-2.13$ & $81(5.64)$ & $108(4.90)$ & 1.20 & $0.95-1.50$ \\
\hline Diabetes & $79(23.72)$ & $130(19.61)$ & 1.13 & $0.87-1.47$ & $204(14.20)$ & $352(15.98)$ & 0.96 & $0.83-1.12$ \\
\hline Asthma & $125(37.54)$ & 209 (31.52) & 1.29 & $1.02-1.62 *$ & $327(22.76)$ & $377(17.11)$ & 1.02 & $0.73-1.44$ \\
\hline $\begin{array}{l}\text { Thyroid and parathyroid } \\
\text { disorders }\end{array}$ & $10(3.00)$ & $23(3.47)$ & 0.86 & $0.45-1.63$ & $151(10.51)$ & $225(10.21)$ & 0.90 & $0.76-1.06$ \\
\hline Chronic kidney diseases & $16(4.80)$ & $38(5.73)$ & 1.03 & $0.62-1.73$ & $47(3.27)$ & $71(3.22)$ & 0.46 & $0.18-1.17$ \\
\hline Chronic liver diseases & $20(6.01)$ & $42(6.33)$ & 1.13 & $0.70-1.82$ & $46(3.20)$ & $56(2.54)$ & 1.51 & $1.12-2.04^{*}$ \\
\hline Autoimmune diseases & $15(4.50)$ & $22(3.32)$ & 0.91 & $0.53-1.55$ & $80(5.57)$ & $99(4.49)$ & 1.13 & $0.89-1.43$ \\
\hline $\begin{array}{l}\text { Malabsorption related } \\
\text { conditions }\end{array}$ & $0(0.00)$ & $6(0.90)$ & 0.00 & $0.00-0.00$ & $12(0.84)$ & $14(0.64)$ & 1.41 & $0.80-2.49$ \\
\hline $\begin{array}{l}\text { Chemotherapy and side } \\
\text { effects }\end{array}$ & $22(6.61)$ & $61(9.20)$ & 1.19 & $0.76-1.84$ & $50(3.48)$ & 109 (4.95) & 1.28 & $0.96-1.72$ \\
\hline $\begin{array}{l}\text { Adverse effect of } \\
\text { glucocorticoids }\end{array}$ & $33(9.91)$ & $29(4.37)$ & 1.96 & $1.33-2.90^{*}$ & $45(3.13)$ & $50(2.27)$ & 1.35 & $1.00-1.85$ \\
\hline $\begin{array}{l}\text { Androgen deprivation } \\
\text { therapy }\end{array}$ & $5(1.50)$ & $5(0.75)$ & 3.05 & $1.24-7.53^{*}$ & $61(4.24)$ & $107(4.86)$ & 1.04 & $0.79-1.35$ \\
\hline
\end{tabular}

\# Model adjusted for age and bed day interaction, no variables violated the proportional hazards assumption. The reference categories were patients who didn’t have co-morbidities ₹ Model adjusted for age and bed day interaction as well as variables which violated the proportional hazards assumption including age, asthma and chronic kidney disease. The reference categories were patients who didn't have co-morbidities. ^ Identified at any hospital admission. ${ }^{*} \mathrm{P}<0.05$. 


\section{Supplementary Material 1:}

ICD-10-AM diagnosis and primary cause of injury codes used to select cases for a definition of minimal trauma fracture (MTF). To meet the criteria for MTF, separations needed to have one of the listed S or T diagnostic codes and one of the W mechanism of injury codes.

\begin{tabular}{|c|c|c|c|}
\hline ICD-10-AM diagnosis codes & Description & $\begin{array}{l}\text { Code for primary cause of } \\
\text { injury }\end{array}$ & Description \\
\hline S02 - excl S02.5 & $\begin{array}{l}\text { Fracture of Skull and Facial } \\
\text { Bones (Excluding Fracture } \\
\text { of Tooth) }\end{array}$ & W00 & $\begin{array}{l}\text { Fall on Same Level Involving } \\
\text { Ice and Snow }\end{array}$ \\
\hline S12 & Fracture of Neck & W01 & $\begin{array}{l}\text { Fall on Same Level from } \\
\text { Slipping, Tripping and } \\
\text { Stumbling }\end{array}$ \\
\hline S22 & $\begin{array}{c}\text { Fracture of Rib(s), Sternum } \\
\text { and Thoracic Spine }\end{array}$ & W02 & $\begin{array}{l}\text { Fall Involving Ice-Skates, } \\
\text { Skis, Roller-Skates or } \\
\text { Skateboards }\end{array}$ \\
\hline S32 & $\begin{array}{l}\text { Fracture of Lumbar Spine } \\
\text { and Pelvis }\end{array}$ & W03 & $\begin{array}{l}\text { Other Fall on Same Level } \\
\text { Due to Collision with, or } \\
\text { Pushing by, Another Person }\end{array}$ \\
\hline S42 & $\begin{array}{l}\text { Fracture of Shoulder and } \\
\text { Upper Arm }\end{array}$ & W04 & $\begin{array}{l}\text { Fall While Being Carried or } \\
\text { Supported by Other } \\
\text { Persons }\end{array}$ \\
\hline S52 & Fracture of Forearm & W05 & Fall Involving Wheelchair \\
\hline S62 & $\begin{array}{l}\text { Fracture at Wrist and Hand } \\
\text { Level }\end{array}$ & W06 & Fall Involving Bed \\
\hline S72 & $\begin{array}{c}\text { Fracture of Femur } \\
\text { (Including Neck of Femur) }\end{array}$ & w07 & Fall Involving Chair \\
\hline
\end{tabular}


Fracture of Lower Leg,

Including Ankle

S92

Fracture of Foot, Except

Ankle

T02

T08

T10

T12

T14.2

Unspecified

Body Regions

Fracture of Spine, Level

Fracture of Upper Limb,

Level Unspecified

Level Unspecified

Fracture of Unspecified
Body Region
W08

W18

W19

W22

W50

W51

Fall Involving Other

Furniture

Other Fall on Same Level

Unspecified Fall

Striking Against or Struck by

Other Objects (i.e.

Excluding Thrown,

Projected or Falling Objects

and Sports Equipment)

Hit, Struck, Kicked, Twisted,

Bitten or Scratched by

Another Person

Striking Against or Bumped

into by Another Person

W54.8

Struck by Dog 